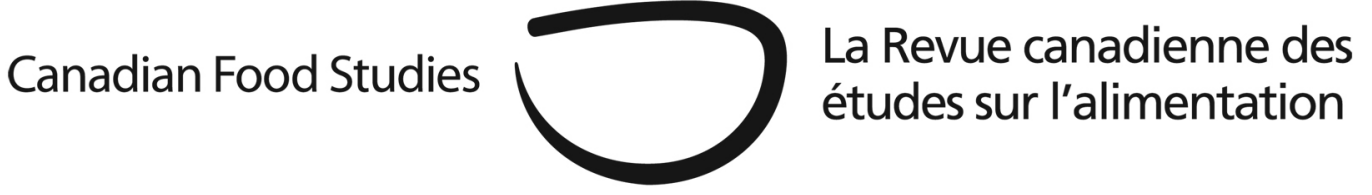

Original Research Article

\title{
Waste management as foodwork: A feminist food studies approach to household food waste
}

\author{
Carly Fraser and Kate Parizeau* \\ University of Guelph
}

\begin{abstract}
Food waste in Canada is estimated to amount to $\$ 31$ billion per year, with approximately half of this waste occurring in households (Gooch \& Felfel, 2014). However, household food waste studies remain underrepresented in the literature, particularly in a Canadian context. This paper calls on feminist food scholars to contribute to this gap by incorporating food waste analyses into their food research. This study uses a photovoice methodology and feminist analytical perspectives to investigate the moment when food became "waste" in 22 households in Guelph, Ontario. Findings suggest that food waste production is representative of forms of foodwork (DeVault, 1991), and that attention to food wasting reveals embodied knowledges of food and interactions with the food system. We contend that scholars and those concerned with household waste reduction should examine and consider how the responsibility for food waste management has been constructed to fall along gendered lines. The intersection of these findings with ongoing research in feminist food scholarship reveals that feminist food scholars are well placed to contribute to food waste studies.
\end{abstract}

Keywords: food waste, photovoice, household, foodwork

*Corresponding author: kate.parizeau@uoguelph.ca

DOI: $10.15353 /$ cfs-rcea.v5i1.186

ISSN: 2292-3071 


\section{Introduction}

It has been estimated that approximately $\$ 31$ billion per year in food is wasted across Canada's food value chain, with 47 percent of that waste occurring at the household level (Gooch \& Felfel, 2014). Wasted food represents a loss of all of the resources involved in growing that food, as well as the potential emission of greenhouse gases when food decomposes in landfills. The scale of food waste in Canada is particularly egregious given that eight percent of Canadian households are considered food insecure (Roshanafshar \& Hawkins, 2015). As food waste gains prominence as an issue of environmental and social relevance, researchers have noted the need for household food waste studies to expand by way of ethnographic research (Evans, 2012; Graham-Rowe, Jessop, \& Sparks, 2014).

Falling neither into the category of distinctly food studies nor distinctly waste studies, food waste discussions can be easily divorced from conversations happening in both spheres. Bridging these two areas of research draws attention to the messiness at the nexus of food and waste discourses. In particular, little attention has been paid to the gendered dynamics that exist in the home around food waste. This paper focuses on how conversations in feminist food scholarship can contribute to understandings of food waste, and thus how feminist food scholars can extend their research on food to include its disposal. We draw on the feminist concepts of foodwork and knowledge production through visceral interactions with food waste. By reframing actions such as eating, cooking, and knowing food as waste management moments, this paper aims to enliven conversations about waste in research on food.

This paper was developed by asking: What happens when we look at food waste through a feminist lens? Brady, Gingras, and Power (2012) ask this question with specific attention to the importance of feminist analysis in food studies. They assert that "(s)cholarly analyses of food, foodwork, and bodies must pay attention to gender because of the centrality of women and foodwork and the resulting gender inequalities" (Brady et al., 2012, p.122), and that "by ignoring food as an area of feminist inquiry, scholars overlooked the important ways in which women produce, reproduce, resist, and transform gender ideologies in their everyday work of feeding themselves and others" (p.123). Forms of foodwork include: "budgeting financial, human and material resources; purchasing and transporting food; assessing the quality of food for purchase; seeking out and using knowledge of nutrition; planning and preparing meals; judging the schedules, likes, dislikes, and various health concerns (e.g., diabetes, low-sodium diet) and dietary needs (e.g. allergies, vegetarianism/veganism) of family members and cleaning up” (Brady et al., 2012, p.127).

In the context of the household, the research of Marjorie DeVault (1991) has had particular influence on studies of gendered work with regard to food and family. DeVault's (1991) research illuminates the foodwork that women do as a form of both care work in the family and physical maintenance of the home. Thus, recognizing foodwork as work contributes to understandings of household labour division. Beagan, Chapman, D'Sylva, and Bassett (2008) explore the division of labour in three ethno-cultural groups in Canada and find that, in all three, 
women still hold primary responsibility for foodwork. Their final remarks are important to keep in mind, as the division of labour in Canadian households is often justified using subtle gendered cues:

For decades, scholarship in the area of domestic labour has assumed gender inequities will diminish over time, yet this does not appear to be happening. Rather, traditional gender roles seem to reinvent themselves in new guises. While it is no longer acceptable in many sociocultural groups to assume domestic work is inherently women's work, the same gender expectations persist in more complex forms, couched in terms of individual choices, standards, and preferences. (Beagan et al., 2008, p. 668)

Presumptions of growing gender equality can undermine the impetus behind gender awareness in research; however, scholars continue to reveal the ways that gender impacts Canadian society (see also McPhail, Chapman, \& Beagan, 2011).

Lewis (2015) warns that the incorporation of gender into research without intersectional feminist reflection can still create positivist results which seek to "manage" social experience. She reminds us that "[i]nterdisciplinary work on gender and food encourages us to make connections between the materialities of food and discourses around food and eating” (Lewis, 2015, p. 424). Thus, feminist food studies incorporate gendered politics into food studies while also questioning ways of knowing and creating knowledge around food. Pulling from and contributing to the work of feminist geography, Hayes-Conroy and Hayes-Conroy (2008) have used feminist politics to delve into the visceral realm of food through taste. They make connections between power in the food system and the way(s) that power combines with individual experience to produce a politics of food in eating. Using food as their entry point, Hayes-Conroy and Hayes-Conroy (2008) assert that "paying attention to the visceral realm can reveal different kinds of knowledges and sensitivities that may be used to inform and enhance political decision-making and lead to more effective socio-political organizing” (p.469).

In ethnographic food waste research, the gendered aspects of how individual responsibility is encouraged to reduce food waste have been tentatively discussed. For example, Waitt and Phillips (2015) explain that food waste reduction campaigns target the individual skills of consumers, mimicking social ideals of what it means to be a good homemaker and citizen: "A good homemaker" and "good citizen” minimises food waste, connecting the everyday practices of refrigeration and ridding with power geometries that shape and reshape home, food systems and subjectivities" (pp. 11-12). In a footnote, they remind readers that "in the households of heterosexual couples, women tended to be mainly responsible for these practices" (Waitt \& Phillips, 2015, p. 19). Similarly, Evans (2012) alludes to the importance of gender by discussing care narratives amongst participants. Terms such as "homemaker” and “care provider” carry a distinctly feminine history which carries forward today. For example, in Canadian households, women spend twice the amount of time cooking and washing up as men (Beagan et al., 2008). It is important to acknowledge that the experiences of women in relation to food waste are likely to 
have a large influence on the production of food waste in the home when they are in the primary position of food provisioning.

Feminist food scholars have developed perspectives on food-related issues that food waste scholarship is just beginning to explore. There is an opportunity for feminist food scholars to contribute to waste scholarship by adding nuance to analyses of the moment when food becomes waste. In particular, feminist food studies allow for a discussion of the social production of food waste, which is embedded within gendered foodwork activities such as shopping, cooking, and provisioning. This theoretical approach also allows for greater consideration of the ways that visceral politics are imbricated with embodied experiences of food and waste.

\section{Methods}

This study investigated how people understand food waste in their everyday lives. In addition to a series of interviews, Fraser carried out an adapted photovoice method (Wang, 1999), asking study participants to document 12-24 moments when they noticed that their food was going to waste, as well as moments relevant to their household's "food waste story" —or overarching themes-over a two-week period. The aims of this research were to:

1. Document the moments of transition between food and waste in households in Guelph, Ontario;

2. Explore relationships between food and wasting behaviours in the household; and

3. Make connections between household food waste and systemic and institutional forces.

The study was conducted in 22 homes in Guelph, Ontario. Prospective participants were approached following a series of waste measurements, audits, and surveys conducted in eight neighbourhoods in Guelph in cooperation with municipal partners. Further participants were recruited using snowball sampling, including social media posts. The study was directed toward the person in the household most responsible for buying and preparing food. Initial interviews collected demographic data and baseline information about household shopping, eating, and wasting behaviours. Participants were then asked to photograph moments of food waste, and these moments were discussed and elaborated on during a second series of interviews. A final meeting provided an opportunity for members to check the interview transcripts.

During the photovoice process, the majority of participants used their cell phone cameras to take photos. Three participants used digital cameras, and one participant was provided with a disposable camera at their request. This method of data collection allows the participant to curate their own food waste narrative. The photos were a springboard for more in-depth conversations about waste. Fraser led participants through a series of questions which built on photovoice 
methodology, and incorporated questions about common findings in other food waste studies. Interviewees were first asked to describe the photos, and were then prompted to elaborate on how the organization of their daily lives contributed to the captured moment of food wasting. These conversations typically led to discussions of shopping, food preparation, meal provisioning, and cleaning up. Participants were asked about the backstory of food preparation or intentions during grocery shopping prior to this moment. They were also asked about who was responsible for different food- and waste-related tasks in the home. Participants were asked about their actions and intentions around disposing of food in various waste receptacles after it was deemed to be waste. These questions were important for bringing together often siloed discussions around food and waste. While at first conversations about food preparation seemed slightly off topic, it quickly became clear that there was no separating discussions of waste from those surrounding all of this preparatory work. While waste production is not commonly perceived as integral to household tasks like shopping and cooking, these interviews highlight the importance of acknowledging waste at each stage of food preparation and procurement.

The data were analyzed using feminist analytical perspectives to understand how understandings of food waste might shift if gendered dynamics of work and visceral knowledge creation were considered. The study was not designed to assess intersectionality as a theoretical framework, and so we did not conduct in-depth interviews to assess participants' identifiers. We believe that the sample is socio-economically homogenous due to the focus on single-family homes within similar neighbourhoods in Guelph. The homogeneity of our sample is a limitation of the study, and suggests that socioeconomic diversity is an important area for future research. All of the participating households consisted of couples, and all households either included small children or were "empty nesters" with grown children who had already left the household. In total, 19 of the 22 of the interview participants were women only, three interviews included both women and men, and one interview was conducted with a male participant. While this was a non-random self-selected sample of participants, the high level of gender imbalance among participants reflects the high level of women's involvement in food procurement, preparation, and waste management in Canadian households.

\section{Results and discussion}

\section{The gendered nature of household "food-waste-work"}

We learned that the gendered nature of food work is sometimes apparent, but is often coded. At times, gendered differences in food waste experiences were mentioned explicitly:

Like talking about food waste and inevitably the word guilt comes up. But I feel like if you were interviewing a guy about this they wouldn't even mention the word guilt ever. It just, they, it seems to be a women thing and it seems to be a mom thing. Like that we feel 
guilt about everything you could possibly feel guilt about.

(Participant 22, 30-39-year-old woman)

Other times, gendered experiences were referred to more subtly through comparison. Participant 10 (30-39-year-old woman) describes:

Like if the kids were eating that I would never just throw that out, or in the compost or whatever, I would always hold onto it to maybe snack on it later in the day or tomorrow whereas my husband would just throw it out because he hates having things go bad. If there's only like half a spoonful of jam left in the container he'll just throw it out, he won't put it back in the fridge. Whereas the way I was raised, you know it's like ingrained into your head, like you save that and someone will eat it eventually and then if it goes mouldy then you throw it out.

The participant does not claim that her actions actually prevent the waste from happening, but the experience of wasting something before it goes mouldy is different between the participant and her husband. This is not to suggest that either women or men are more or less likely to waste food. Rather, as highlighted by this example, there are differences in experiences of food wasting within a household. There is also variability among women in terms of their likeliness to waste food (see Evans, 2012; Waitt \& Phillip, 2015).

Beyond this difference in experience, interviews revealed how certain people's politics may have more influence on the household's actions. During an interview, Participant 17 (30-39year-old woman) tried to draw similarities between the thriftiness she saw in her family and her husband's family, and the impact of those similarities on their own household food waste production. While her husband recognized that his family had a mentality of "you don't throw things out, you fix them", he did not feel this history had influenced his actions with regard to wasting food as much as his wife had thought. Finally, the participant conceded: "it sounds like I have more influence on our household's food consumption, waste decision than he does (laughter)" (Participant 17, 30-39-year-old woman). Her implication is that a mother figure has greater socialization influences on domestic consumption than a father figure would. It is important to recognize that these histories of food waste are inscribed with gendered socializations, and with expectations of enacting these socialized histories. As Beagan et al. (2008) note, it is common for people to disregard gender because they perceive divisions of household labour as fair or justifiable. Regardless of how participants feel about the equity of gender division in food waste activities in their households, it is still important to pay attention when a gendered distinction exists in households. The importance of highlighting these differences, however, is less about who prepares the food, and rather how knowledge about food and waste has been produced and is continuously being produced in society. There is work that goes into food waste production that is part of traditionally unacknowledged domestic labour. In the following sections, we describe this work through examples of explicit and implicit waste management during the process of domestic food handling. 


\section{Waste work as explicit waste management}

Explicit waste management includes actions that participants did in response to both the potential and the emergence of waste. Along with the need to dispose of food exhibiting certain characteristics (such as decomposition), there were also times when aesthetic and/or material decomposition signalled the need to manage the food item to facilitate future use and avoid waste.

While the majority of photos were not indicative of waste avoidance, during the interviews some participants explicitly discussed how waste avoidance factored into their household's food waste story. Two participants revealed specific photos of food waste avoidance in relation to their food waste story. One photo was of a smoothie made with leftover oatmeal portions from their young toddler (Figure 1). The other was of peaches being made into compote (Figure 2). The participant responsible for the smoothie took great pride in adapting her family's breakfast in response to food waste:

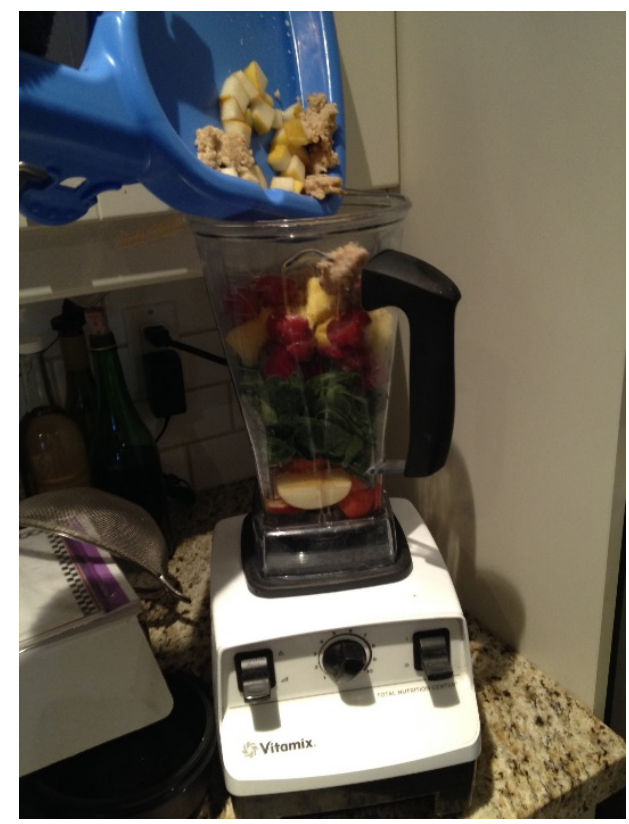

Figure 1: Leftover smoothie, Participant 17, 30-39-year-old woman

We always have tonnes of baby leftovers. Crusts, oatmeal, things that don't get eaten, fruit and what we've started doing is we make a smoothie every morning [...] and whatever leftovers we have we collect them in the fridge and then dump them into the family smoothie the next day. So this is just a picture of saving tray randomness and putting it inside the smoothie [...] it's a way that we feel really good about preventing food waste. (Participant 17, 30-39 year-old woman) 
Notice that, to avoid waste in this case, the participant has developed a specific strategy. This strategy requires extra (and arguably gendered) work beyond the first round of work that went into preparing the initial meal.

The participant responsible for the peach compote revealed that her husband does not always understand the full extent of why she chooses to preserve:

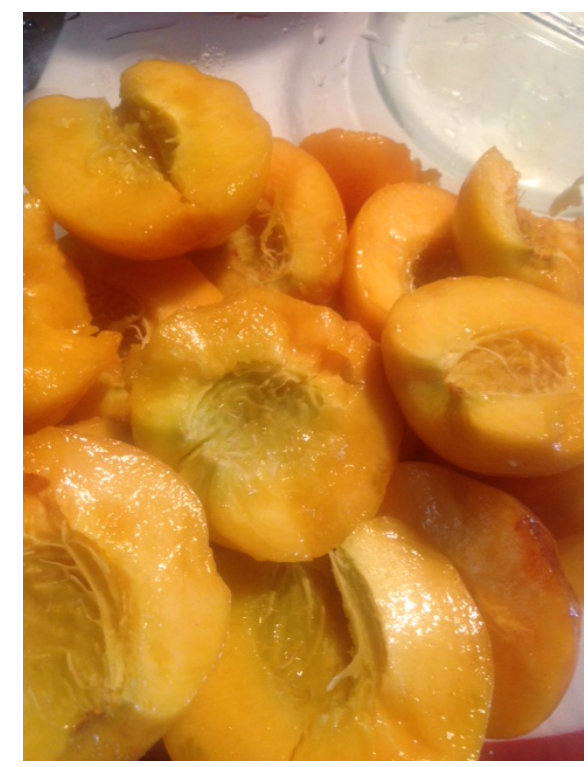

Figure 2: Peach compote,

Participant 7, 20-29-year-old woman

To him it seems like I'm doing all this extra work or whatever. It's not doing it for fun, it's so that a) we don't get fruit flies in the house and b) so that the peaches don't go bad because if I blanch them and put them in syrup then I can save them for longer. Like I have peaches, I have honey syrup-ed peaches in the fridge and I can feed those to the baby but a lot of the time he doesn't realize that I've preserved things. So I have freezer jam in there and I'm sure that he just won't touch it. So I have to like explain to him this is what this is and how you use it and that kind of thing. (Participant 7, 20-29-year old-woman)

Her account challenges the notion of benevolence that often serves to devalue or disregard the actual work that goes into feeding a family and maintaining/managing household resources (the belief that a person enjoying the work detracts from the labour involved, and can lead to an assumption that it will be done regardless of the effort expended to make it happen) (Brady et al., 2012). It also acknowledges the skills and knowledge that are required to preserve and freeze as a waste prevention mechanism.

During the interviews, participants discussed waste management strategies that included using their freezer to store leftovers, preserving items that were going off, and using up food before it could go bad. At times, these management strategies were brought into discussion by 
asking about "almost waste moments"-food that might have become waste if it had not been handled at a particular time or in a particular way. Indicators of food going off but still being usable varied from household to household, but generally included things like "squishy" parts, eyes of potatoes, and bits of mould. A couple of participants revealed that they were able to preserve entire fruits that were going soft, or properly blanch and freeze vegetables that were starting to wilt, but not all had or highlighted this skill. Participants often cooked items that were "not as fresh", such as wrinkled bell peppers, and served them as a simple and effective way to make use of aesthetically degraded items that otherwise would be eaten raw, or continue to decompose and become inedible.

Sometimes, waste management strategies were developed to accommodate retail particularities. For example, an older couple cooking for just the two of them describe the storage of breads:

[...] we'll get a loaf of bread, we'll take half of it out, and put half of it in the freezer. And when that one's gone we'll [take] this one out. Same with hamburger buns, we'll put them on a tray and freeze them separately, and fire them in the freezer so that they keep. (Participants 11, 60-69-year-old couple)

This is an explicit waste management strategy in response to incompatible grocery store portion sizing. This action requires knowledge about which items can be saved in the freezer and managing the freezer so that the bread does not get damaged, for example by being freezer burnt. Freezing, preserving, eating leftovers, and making new meals from leftover items are some of the strategies of waste avoidance, as identified by Quested, Marsh, Stunell, and Parry (2013) and Evans (2012). In particular, these strategies are important to Evans (2012) because they show that, despite the ability for households to place their organics in waste receptacles, many still go to great lengths to avoid wasting food. This shows how individuals must do work to accommodate the surpluses inherent in the modern food market.

Food waste management also includes disposal. Cleaning out the fridge, managing the green bin, and diverting waste into appropriate waste streams all comprise "food-waste-work" which enables flow of the household. Participant 6 (50-59-year-old woman) highlights the separation of her coffee grounds for use in her compost (Figure 3), as well as the minimization of liquid coffee waste: 


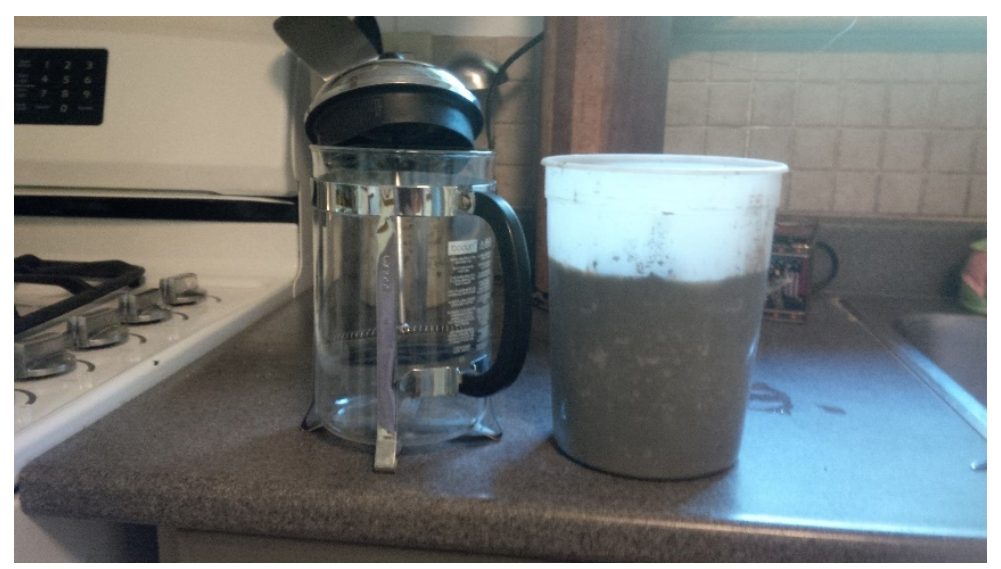

Figure 3: Coffee grounds for compost,

Participant 6, 50-59-year-old woman

So those coffee grounds, first of all we don't waste any coffee in our household. My husband and I each take a thermos of it to work and if the Bodum has coffee left at the end of the night it goes in the cup and it gets covered and it gets saved; we don't throw coffee out. No coffee gets wasted but the coffee grounds do go out to my composter [...] When I've got company and my kids are around [...] we may go through three or four of them, but no coffee goes down the drain. It gets used. If it hasn’t been finished it gets nuked up later.

These actions contribute to waste minimization as well as to nutrient recovery. Participant 20 (60-69-year-old woman) articulately describes the actions she takes around the green bin:

Here I'm doing the peach because the peach is wet and juicy you can see the water, the juices dripping down here. So again I've put that on a paper towel, and then I will wrap that up before I put that into my kitchen bin. So I don't have too much wet [green bin material]. And then that is what it looks like when I put it into my kitchen bin. So I've got the newspaper inside the plastic bin, and then the food here so I've got peach skins, whatever else, banana peels that kind of thing? That will go into the wet, which stays in my kitchen until I take it to the garage.

Her actions align with Metcalfe et al.'s (2013) discussion of the ways that consumers respond to the agency of the green bin by managing its location and creating routines. The installation of a garburator - an in-sink waste disposal unit—in Participant 13's (60-69-year-old man) home is an example of a waste management decision that was made despite the availability of the green bin system. Metcalfe et al. (2013) propose that rejecting the bin altogether is a form of agency.

Explicit waste management strategies require particular action regarding food preservation, handling, and rotation, as well as time and energy to execute this knowledge if food waste is to be completely avoided. This has been acknowledged by ethnographic food scholarship (e.g., Evans, 2012; Waitt \& Phillips, 2015); feminist food scholars need only look a 
little further to link food waste management to their analyses of foodwork. Participants in this study had varying ranges of food knowledge and handling skills that they used to manage or avoid food waste. Furthermore, once food waste is produced, it must be managed in particular ways to accommodate things like fruit flies, odours, and juices. Participants in this study did this by tending to their green bins, composts, and garburators. They also cleaned their fridges and developed strategies of disposal in their household. These explicit waste management strategies are clearly a form of work done in the home, and should be considered foodwork in the home. Furthermore, the interview data suggest that the responsibility to develop and act on such waste management strategies often falls upon women, suggesting that waste management is another gendered form of foodwork in the home.

\section{Foodwork as implicit waste management}

Beyond the explicit mention of food waste avoidance strategies, there were also actions that implicitly led to waste management (though not always complete waste avoidance) in participants' households. While we asked participants to include photos of anything that affected their household's food waste story, participants tended to focus more on items of food gone to waste. We had anticipated some photos of trips to the grocery store, cooking practices, and meal times, because these were the activities often studied by researchers in relation to household food waste in ethnographic studies (e.g., Evans, 2012; Graham-Rowe et al., 2014). Nevertheless, there was ample opportunity to discuss these moments of foodwork further during the interviews. The following are examples of instances where food waste generation co-exists with instances of shopping, cooking, feeding, and eating. Since these actions have already been justified as foodwork by food scholars such as DeVault (1991) and Brady et al. (2012)., in this section we pay particular attention to how this foodwork is also an aspect of waste management. In some cases, this is done by contesting the common idea that food waste emerges simply out of 'error' or poorly performed foodwork, and in others by highlighting the skill that is required to avoid waste.

\section{Shopping as implicit waste management}

Shopping for food is a form of household work that is often overlooked, but is considered a form of foodwork (that is gendered as feminine) (DeVault, 1991). Participant 17's (30-39-year-old woman) experience of shopping for Thanksgiving dinner suggests how shopping is also waste work. Participant 17 was cooking Thanksgiving turkey to bring to a small Thanksgiving gathering. She says:

I decided to go to No Frills, but they decided the size I needed. Right? I wouldn't have bought a turkey that big but that's all there was and you've got to make a turkey on Thanksgiving. So I ended 
up buying an 18-pound turkey (laughter). (Participant 17, 30-39year-old woman)

Under the social conventions that require a turkey be served at Thanksgiving, she had to work within the limits of what was offered at the grocery store. This is an example of the influence of retail outlets on socio-cultural norms. When shopping, participants are working to make decisions based on a variety of factors, and food waste management may or may not be a priority. At the time of the interview, the participant had an overwhelming amount of turkey that she was trying to use up; she was unsure how much would get eaten, and was aware that some might end up going to waste. To avoid such an incident, the participant could have ordered a smaller turkey earlier, gone to a different grocery store, or avoided cooking a turkey altogether. However, all of these decisions require trade-offs around factors such as available planning time, economic means, and social expectations. The degree of one’s “success” around shopping depends on which factor is valued most. If food waste avoidance is the ultimate objective, having the perfect-sized turkey is most desirable. If provisioning for a family holiday is the priority, having any amount of turkey is the priority. Indeed, these priorities may co-exist, and may result in extra effort or strategy development to accommodate both feeding the family and food waste avoidance. Shopping is bound to food waste generation through over-purchasing, and it also requires knowledge of many aspects of food quality, price, and edibility both at the grocery store, and in relation to individual family expectations and eating dynamics. Such skills are expected of the person responsible for food provisioning in the household, which is often a gendered responsibility that falls to women.

\section{Cooking as implicit waste management}

Participants in the study had a range of cooking skills. Some self-identified as highly skilled cooks and others as very "plain and simple”. Some were trained professionally in kitchens, and some were in the processes of learning to cook for their family. Cooking in relation to food waste is particularly noticeable when items are in need of being "used up". Participant 23 (30-39-year old-woman) used to plan out meals for her family, but has since decided to cook based on whatever is in the fridge. Here, she describes her cooking:

I guess every night when I'm thinking about what I'm going to cook for dinner-because I often don't plan ahead anymore-I look at what's in my fridge and I look at what's most perishable and I try to use that first, right? So if I bought both broccoli and cauliflower at the grocery store because both were a good price that week - it's only really down to price-if I bought both that week and I make an effort to make the broccoli first because it's more perishable. So I will often as I'm getting ready to prepare dinner, I'll take a quick look in my crisper drawers and think, ok what do I 
need to use up? And then try to do something there. (Participant 23, 30-39-year-old woman)

Participant 23's cooking requires knowledge about which items are most perishable and in need of being used. She also notes that she cooks based on food prices when shopping. Cooking in this case also requires knowledge of how to come up with a recipe from available ingredients that are time sensitive, thus highlighting waste avoidance work.

In the following story, the foodwork involved in cooking is highlighted in contrast to the other person in the household:

My husband doesn't necessarily, he’s a good cook but he doesn’t necessarily know how to do stuff so like if I've got like a chicken, a seven-pound chicken that's free range and whatever that I've been talking about bringing, he's not going to do that. Because he doesn't know how to do that. And he'll be afraid that he's going to ruin my $\$ 50$ chicken. But if we cook the chicken, if we had done it last night, or if I get it done tonight and roasted and done, then he'll use it for stir-fries and we'll like use it all week, and then next weekend I'll make a stock and then it's fine. (Participant 9, 30-39year-old woman)

The above quote highlights assertions made by DeVault (1991) that cooking requires particular sets of knowledge and skills that are valued in a professional setting, yet undervalued in the home (as often happens when tasks become feminized in a domestic environment). In the home, the work that goes into foodwork is noticed most when it is not done properly. With particular attention to food waste, awareness of unskilled cooking could come in the form of food waste generation, or if someone becomes ill from an item gone bad.

\section{Provisioning as implicit waste management}

Beyond just shopping, provisioning also refers to the serving and feeding of food. In participants' photos of leftovers and plate scraps, what was missing was an image of the food/meal before it was partially consumed. It was therefore unclear how much of the provided food was consumed prior to the participants' identification of the leftovers or scraps as waste, so questions were asked about the lead up to (or backstory around) the photo. Upon reflection of a picture of their salad bowls (Figure 4), Participants 9 (30-39-year-old couple) discussed the amount of vegetables that were consumed before the picture was taken. They revealed that the bowl was probably full, and so a lot was consumed. They remarked on the amount of salad their family consumes, and the female participant commented that she needs to "get better at [her] estimation skills”, noting there is always a bit of salad left at the end of a meal. 


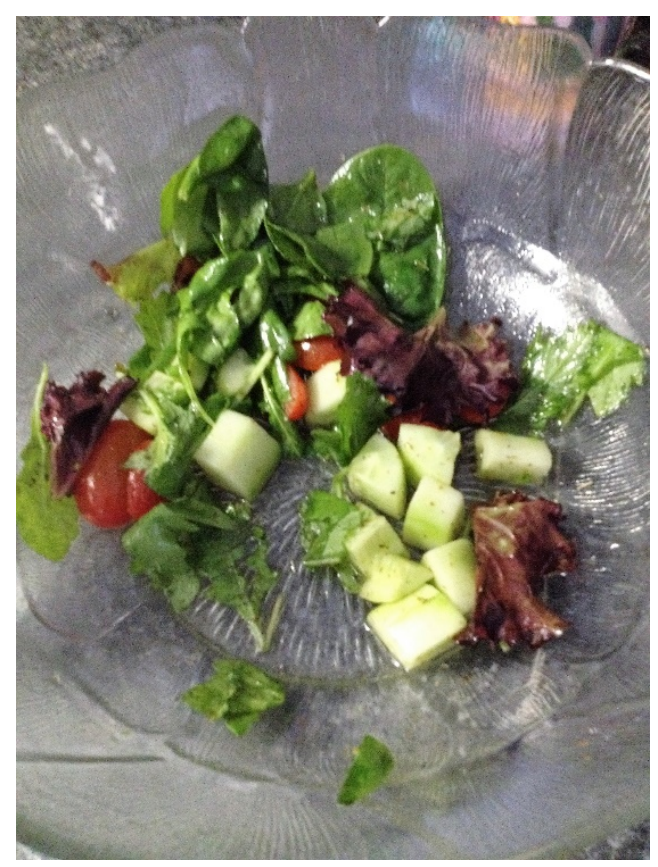

Figure 4: Leftover salad, Participants 9, 30-39-year-old couple

Viewed from a food waste management perspective, the salad has been successful for the most part: the act of provisioning has transferred to almost complete consumption of the salad. This family takes pride in having salads with their meals as they are working to make healthier choices for their daughter. On one hand, to the participant, the leftover salad is a sign of poor estimation; on the other, it is a sign that the family is following through on their commitment to eating healthily.

Provisioning “errors” also emerged when discussing children’s plate scraps. Participants often spoke of their parenting style as either contributing to or lessening waste production. Parenting style pertained to how participants with children decided to feed them (which is another aspect of gendered foodwork in the home). Some participants chose to portion small amounts to their children in order to minimize waste. Other times, they felt that it was important to let children learn on their own how much to put on their plates. This could potentially lead to more waste, but it was described as part of a learning process.

Participant 14 (20-29-year-old woman) describes the challenges of balancing the food preferences of her family with her desire for them to eat healthier. Her exasperation around a moment when pizza went to waste emphasizes the gendered burden of food provisioning in a moment of food waste:

[...] the hubby came home with pizza. And I go: we don’t eat pizza. And then no sooner did he do that my mom came in: hey I bought pizza for everyone! And I looked at everybody and I was like, do you not realize what I'm trying to do here? I cook you guys healthy meals, we have a full fridge of healthy stuff, we have fruits 
all along here. Am I the only one that eats these really? And then I felt so bad that the pizza was going to waste that I ended up having two slices the one day and two slices the other day and it just sat there. And I, by the time-I just can't [eat] more, I can't, and I know I'm going to blow up like a puffer fish because that's how pizza reacts with me, it's done. And then nobody else was eating the pizza so that was what was left after all the pizza fads.

(Participant 14, 20-29-year-old woman)

This participant is describing an unmet ideal for gendered foodwork: the provision of healthy family meals. In this case, the ideal is unrealized because the outside introduction of fast food displaces healthy food from the family meal. Furthermore, this woman also (unsuccessfully) takes on the burden of preventing the pizza from going to waste by eating it herself, even though its ingestion has a negative and embodied effect on her; women's bodies are often a politicized site of food provisioning. In addition to a provisioning conflict between the participant and her husband, implicit in this quote is the intergenerational tension between a mother who is actively working to provide healthy food for her family and prevent food waste, and her own mother, who has a different relationship to the household's foodwork, and so arrives with a treat for her grandchildren.

Parents found it hard to balance variety and exposure to new foods for their children with food waste minimization. Occasionally participants would comment that they could change the way they fed their children, but for the most part food wasting was an expectation of feeding children. Thus, by being structurally tied to children's eating, parents in the role of food provisioners have heightened connections to food waste management (this is also noted by other food waste scholars, such as Evans, 2012).

\section{Eating as implicit waste management}

Eating is also a form of food waste management. The preparatory work of shopping, cooking, and provisioning of food only leads to waste avoidance if the food is actually consumed. This idea is captured by Participant 22 (20-29-year-old woman):

[...] usually I make a meal plan and then I go and buy. So I'll usually make a meal plan and plan out our meals and then I'll go buy whatever we need [...] and then I'll make the meals [...] I don't think that we have a lot of food that we buy that we don't eat. Usually we eat it, or we prepare it in some way and I end up throwing it out. I don't think I'm over-buying, it's just a matter of if it gets eaten or not after it gets prepared.

This sentiment was echoed by many participants in the interviews, particularly around leftovers in the fridge and table scraps. It may seem simple and obvious that food waste is the result of food that does not get eaten, and therefore eating food is food waste management. 
However, eating as a form of waste management is quite complex. For example, Evans (2014) discusses the transitions that food undergoes from surplus to excess to waste. In this process, there is a gap in disposal whereby surplus food is viscerally transformed into something inedible, and therefore excess and disposable. This process is a result of both the material properties of food that allow it to rapidly decay, as well as a series of conscious or subconscious decisions that a person makes to prolong the not-eating of surplus food (e.g., allowing leftovers to languish in the fridge), allowing for decay. In a similar vein, Cappellini and Parsons (2012) describe the eating of leftover foods (and therefore the interruption of their decay) as an act of sacrifice that demonstrates family membership and belonging; these acts are usually performed by mothers, thereby allowing other family members to enjoy fresher foods.

Eating as a form of food waste prevention is also made complex by the limitations of the human body. As Guthman (2011) points out, “... markets for food cannot be infinitely expansive because there are limits to how much food any one person can eat, certainly at a sitting and possibly over time” (p. 181). The body thus presents a challenge to attempts to avoid food waste because, for a variety of reasons, it is not possible to eat all food that is available. Examples throughout this study reveal how bodily limitations might produce food waste (for example through plate scraps and children's leftovers), and how the various processes leading to food waste might also limit its consumption (from mould, rot, and smell, to preference, routine change, and time constraints). The gendered foodwork labour performed in households is therefore embodied in family members' affective and physical states, as well as in the materiality of meals provided and food waste generated.

A focus on eating also reveals how food waste management in the home is structurally determined. For example, Participant 16 (30-39-year-old woman) reveals that when she does not eat leftovers, they go to waste:

[...] if it's a leftover that I'm not quite as fond of-because I'm the one that's home during the day and cooking lunches at home- $\mathrm{I}$ tend to consume more of the leftovers. So if it's something I don't like quite as much it might not get consumed in its entirety.

This was stated offhandedly by the participant during the interview; she does not necessarily have a desire for help in consuming the unwanted leftovers. However, such instances highlight that relationships to food waste differ between various actors in the household. For example, the above comment reveals that Participant 16 eats the majority of the leftovers in the home because she is at home during the day. In a similar encounter with one of his participants, Evans (2012) reasons that: "One might wish to argue that [this participant] could stay at home, eat the leftovers and so prevent them from becoming [waste]. However, arguments such as these—quite aside from lacking humanity and empathy—miss the point that as a "housewife", [this participant] is structurally at risk of boredom and isolation” (p.44). There is responsibility for those closest to food procurement and provisioning to consume (eat) and to foster consumption (eating) in others. Scholars such as Jackson (2015) show how this structural responsibility is also carried in the body through the guilt and anxieties that surround wasting 
food. The responsibility of food waste management in the household is unevenly distributed, often along gendered lines.

\section{Visceral politics}

The work of food waste production and management is informed by a visceral politics of knowing food, which has a gendered history (Hayes-Conroy \& Hayes-Conroy, 2008). While they do not explicitly acknowledge this gendered history, Waitt and Phillips (2015) have explored visceral experiences of food wasting with specific attention to acts of disposal around refrigeration. They describe the visceral response to food waste by a participant in their study as "embodied knowledge involved in judging edibility, the variability of such assessments, and the affective force of food transforming through cellular and bacterial processes" (Waitt \& Phillips, 2015, p. 2). This section will show how senses, past histories, and experiences with food and waste come together in a visceral moment of food waste. With particular attention to the development of taste affinities, Hayes-Conroy and Hayes-Conroy (2008) assert that:

In the visceral realm, representations join and become part of old memories, new intensities, triggers, aches, tempers, commotions, tranquilities. In the visceral realm, representations affect materially. The visceral body feels them as intensities that have an impact on tasting. (p. 468)

In this study, participants noted that taste was used to decide whether a food item was worth eating or not. In some cases, taste acted as a justification for forgetting about a food, with comments indicating that the food item "wasn't that good anyhow.” These comments relate to Evans' (2012) discussion of purposeful forgetting, and the power this has to assuage guilt that may arise when wasting food. The taste of food items influenced the amount of the item that would get consumed, which in turn could lead to wasting. For example, corn was wasted because it was "woody" (Participants 11, 60-69-year-old couple), and watermelon was consumed in its entirety when "red, juicy, [and] delicious" (Participant 5, 40-49-year-old man). Thus, the visceral intensities Hayes-Conroy and Hayes-Conroy (2008) identified around tasting food also have an effect on the material afterlife of food, particularly as experienced by women during food handling.

Other common visceral intensities around food wasting include overwhelming sensations, such as disgust, that manifest and influence trajectories of wasting. Participants' visceral responses that led to categorizing food as waste (and thereby leading to disposal) were triggered by the sight of fruit flies, mould, or the inhalation of a strong rotting smell in participants' food waste stories. For example, the experience of encountering disgust can be seen and described through the following photo (Figure 5) and story: 


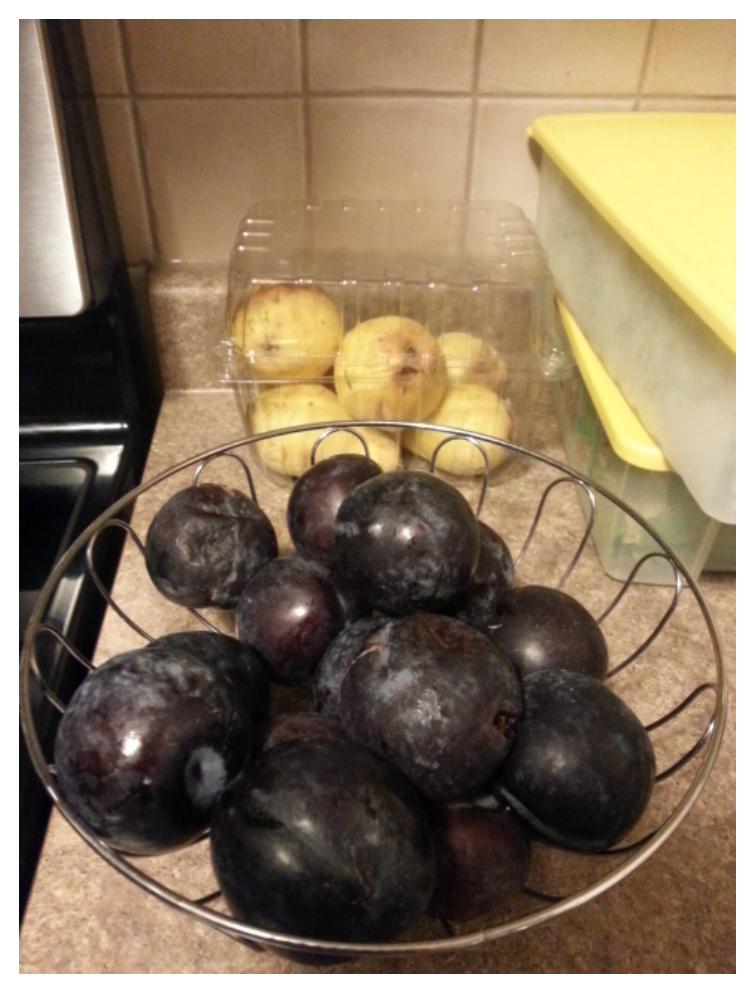

Figure 5: "Oh my god, those are done", Participant 22, 20-29-year-old woman

Ok well this is going to sound gross (laughter), these plums were leaking all over our counter. The bottom ones had actually started turning into juice. They were gross and they were covered in fruit flies. So yeah so they had to go. The top ones had like little specks or chunks out of them which the fruit flies were all over. So it was definitely, it wasn't even on the fence, it wasn't a maybe, it was like an: oh my god those are done. (Participant 22, 20-29-year-old woman)

In this case, the sight of fruit flies produced a reaction that meant there was no way the plums were going to get eaten. Waitt and Phillips (2015) discuss how processes of decay are "reminders of foods' vitalities" (p. 2). The response to such reminders can vary greatly depending on the food item, as well as on the person handling the food, and affect waste production and disposal trajectories. Participant 2 (30-39-year-old woman) was fairly diligent in paring foods when she noticed mould or was not pleased with the appearance of the food item (Figure 6). Nevertheless, the emergence of an unfamiliar encounter with food provoked some uncertain scenarios that led to disposal: 


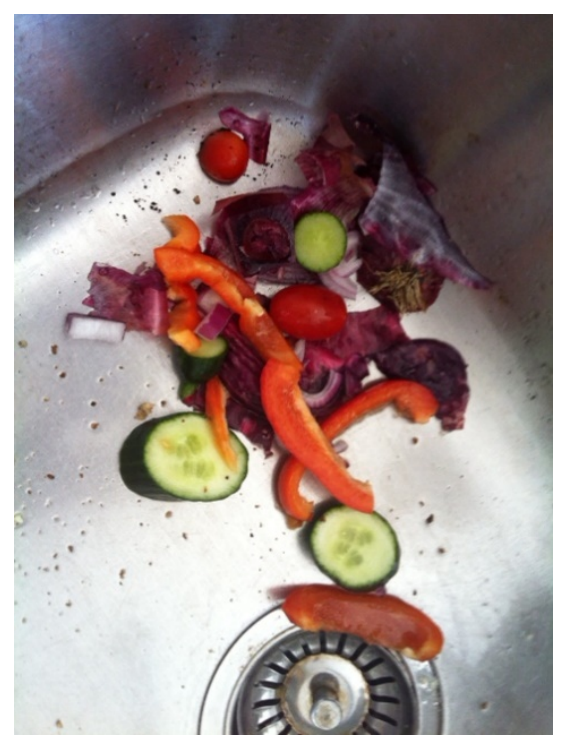

Figure 6: Vegetable parings, Participant 2, 30-39-year-old woman

I cut up a little bit more of the red onion because it was a little bit milky. I looked it up afterward and it's fine, it just means it will have a stronger flavour to it. But I didn’t like the look of it at the time. So I did cut off a little bit more because it was milky, and I had never ever seen that in an onion before. (Participant 2, 30-39year-old woman)

Here, the milkiness of the onion prompted the participant to be more liberal in her paring of the onion: a minor adjustment, but a change nonetheless. Visceral responses can also contribute to disposal of waste into a particular conduit (Figure 7), as described here:

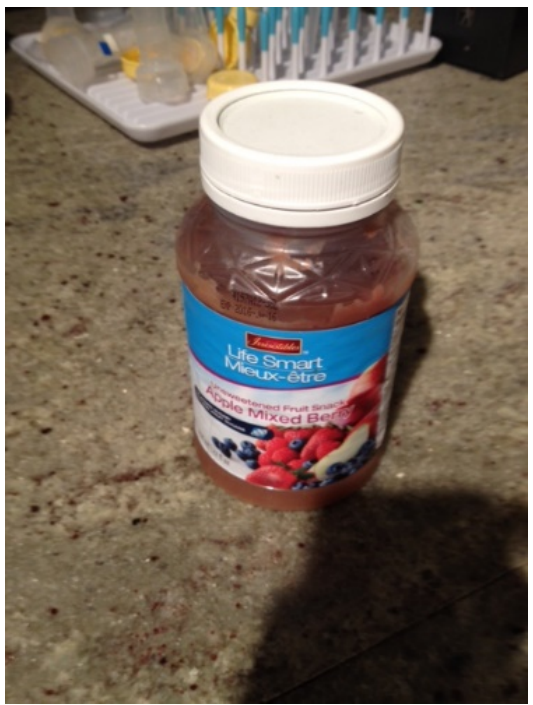

Figure 7: Mouldy applesauce, Participant 18, 30-39-year-old woman 
This was applesauce that had been in the fridge for a very long time. And I looked at it. I was afraid to open it because there was mould on it, so I didn't even look. I just put it right in the garbage. (Participant 18, 30-39-year-old woman)

When asked to follow up on this moment, she went on to say:

So when I see mould, I gag, like really bad. It's gross. So I couldn't even open it because I knew I'd start that process. So I could have scooped it into the green bin but with that I just can't. It's too gross. So I had really no choice but to put it in the garbage. Plus it was already in a container so it was easy. (Participant 18, 30-39-yearold woman)

This visceral response was so strong that the participant felt she had "no choice" in the matter of where the applesauce would be disposed. Despite her initial ambivalence, in her final estimation, the only place the participant could dispose of the applesauce was in the garbage. This shows how visceralities can override intentions to be rational, or environmental, or sort "properly", thereby affecting the material afterlife of food. Visceral interactions have the power to determine whether an item will be eaten, then whether it will be used for compost, or sent to landfill where improper conditions for decomposition lead to the release of methane gas (Hall, Guo, Dore, \& Chow, 2009). Visceralities serve as conduits to disposal that have power even over infrastructural developments that divert waste (such as the green bin used for municipal organics diversion).

In the case of the plums (Figure 5), onion parings (Figure 6) and applesauce (Figure 7), reactions emerged in response to the physical presence of foods' vitality. Food waste was also conjured by visceral anticipation of experiences, such as disgust, in participants' stories. For example, Participant 23 (30-39-year-old woman) describes a change in her habit of using smell to decide if an item is still edible or not:

[...] the whipping cream I knew had been opened about the same time so I didn't even bother sniffing it [...] I had a few instances in the last three months where I opened up like a sippy cup of milk that had just little bit of milk in the bottom, and then I made this mistake of sniffing it, and I smelled the sour milk and vomited. A lot. So I didn't want to sniff it because I had this feeling it would make me vomit so I didn't sniff it in this case.

Her previous experience with sour milk created a strong immediate reaction at the time (vomiting), but also carried over to future instances. It was not worth it to test through smell if the whipping cream had gone bad when, based on time estimates, she already assumed it had. This shows how experiences conjure anticipation of visceral encounters, which alter the interactions we are willing to have with food to know whether it is still edible or not.

Similarly, Watson and Meah (2013) describe the visceral experience of food waste specifically around the issue of date labels. They state that "for all respondents boundaries exist, 
even if they are often defined by the affective experience of disgust more than cognitive reflection on bacterial risks" (Watson \& Meah, 2013, p.6). The differences in "boundaries" can be seen when Participant 2 (30-39-year-old woman) describes her husband's willingness to disregard lunch meat best before dates and her own reluctance:

[...] like lunch meat is a big thing, I don't push lunch meat. I think after like 3 days... 4 days is the most that I'll eat it. He'll eat it after the fifth day and I'm like you are going to get sick. But he has this moral...so he'll push it [...] so then we eat separate meals. Like a couple days ago we had separate meals because I'm like I'm not eating that. That's over the shelf life.

Recall that Participant 2 (30-39-year-old woman) is fairly comfortable paring bruises from fruits and vegetables, and slicing bits of mould off of cheese. In this case, food safety, time constraints, and risk were provoked through the participant's interpretations of the "best before" date. This instance reveals the power that date labels have in constructing visceral responses to food waste. Although best before dates are not firm lines marking food's transition from edible to inedible, discourses have developed around best before dates such that they are relied upon for judging when food is good and safe (Milne, 2013). Thus, best before dates create more visceral conduits of disposal by changing ways of knowing whether food is still edible or not.

Importantly, date markers can create diverse visceral experiences in different people: some see best before dates as irrelevant to the edibility of food, some see them as one mediating factor in the material status of food, and others see best before dates as constitutive of whether a food is still intact and palatable (see also Evans, 2011). This example demonstrates that viscerality has a cognitive component: factors like guilt, worry, shame, and intellectual justifications for wasting are interrelated with the sensory viscerality of food waste, and are inherent to the processes that determine the moment when food becomes waste.

These visceralities are informed by interventions in the food system that have gendered impacts. For example, date labels have often replaced the feminized knowledge of understanding edible and/or "safe" food acquired through food handling and prep-work (Milne, 2013). When food waste reduction campaigns primarily target individuals, they are ignoring that "wasteful" outcomes of visceral responses are reflexive of cultural shifts that have been implemented over time to, for example, promote food safety, or produce profit (by encouraging household disposal and replacement of certain foods). Particularly when the gendered effort to work through these complex social messages has been historically un(der)valued, it is worth considering the increase in gendered food-waste-work invoked by focusing food waste reduction efforts at the household level. 


\section{Conclusions}

Through the extension of a feminist framework, this paper has shown that food waste management is a component of foodwork, and that various forms of foodwork also contribute to food waste management. The performance of foodwork carries a distinctly feminine history, and DeVault (1991) asserts that "[t]he work is noticeable when it is not completed (when the milk is all gone, for example, or when the meal is not ready on time), but cannot be seen when it is done well” (p. 56). Food waste becomes representative of poorly performed foodwork when attention is not paid to the supporting work that goes into food's procurement, preparation, and provisioning. Scholars show how “...disregard for unpaid foodwork as real work renders the persons held responsible for it (mainly women) of less consequence than those who are ideologically positioned as family breadwinners (mainly men)” (Brady et al., 2012, p. 127). Moreover, purposeful deskilling campaigns have limited the social access that food provisioners have to knowledge translation around cooking (Jaffe \& Gertler, 2006), including visceral knowledges of what is "good" and "edible” food. This deskilling undermines the potential for food-waste-work to be performed expertly in order to reduce food waste in households.

The application of a feminist lens to household food waste reveals that waste management is also foodwork, and that this labour is gendered. The viscerality of waste also influences our knowledges of food in ways that are connected to food consumption, as well as to values of providership and stewardship of household resources. We observed that female participants produced and reproduced gender ideologies in the everyday work of feeding themselves and their families (and in the attendant waste production that is inherent to this foodwork). In some instances, they resisted the transformation of food into waste by applying additional gendered labour, or by eating excess food themselves; such transformations also served to perpetuate gendered expectations of female sacrifice in the domestic sphere. Such tensions between the imperatives to prevent and create waste are often borne by women, and are an often overlooked aspect of the gendered balancing acts involved in managing household resources. Recognizing the role of gender in preventing and managing household food waste contributes to feminist food studies, to waste studies, and to efforts to effectively intervene in the generation of food waste.

\section{References}

Beagan, B., Chapman, G. E., D’Sylva, A., \& Bassett, B. R. (2008). “It’s just easier for me to do it”: Rationalizing the family division of foodwork. Sociology, 42(4), 653-671.

Brady, J., Gingras, J., \& Power, E. (2012). Still hungry: A feminist perspective on food, foodwork, the body, and food studies. In M. Koc, J. Sumner, \& A. Winson (Eds.), Critical perspectives in food studies (pp. 122-135). Don Mills: Oxford University Press Canada. 
Cappellini, B., \& Parsons, E. (2012). Practising thrift at dinnertime: Mealtime leftovers, sacrifice and family membership. The Sociological Review, 60(2S), 121-134.

DeVault, M. (1991). Feeding the family: The social organisation of caring and gendered work. Chicago: Chicago University Press.

Evans, D. (2011). Blaming the consumer - once again: The social and material contexts of everyday food waste practices in some English households. Critical Public Health, 21(4), 429-440.

Evans, D. (2012). Beyond the throwaway society: Ordinary domestic practice and a sociological approach to household food waste. Sociology, 46(1), 41-56.

Evans, D. (2014). Food waste: Home consumption, material culture and everyday life. London: Bloomsbury Publishing.

Gooch, M., \& Felfel, A. (2014). “\$27 billion” revisited: The cost of Canada’s annual food waste. Guelph: Value Chain Management Centre International.

Graham-Rowe, E., Jessop, D. C., \& Sparks, P. (2014). Identifying motivations and barriers to minimising household food waste. Resources, Conservation and Recycling, 84, 15-23.

Guthman, J. (2011). Weighing in: Obesity, food justice, and the limits of capitalism. Oakland: University of California Press.

Hall, K. D., Guo, J., Dore, M., \& Chow, C. C. (2009). The progressive increase of food waste in America and its environmental impact. PloS One, 4(11), e7940.

Hayes-Conroy, A., \& Hayes-Conroy, J. (2008). Taking back taste: Feminism, food and visceral politics. Gender Place and Culture, 15(5), 461-473.

Jackson, P. (2015). Anxious appetites: Food and consumer culture. London: Bloomsbury Publishing.

Jaffe, J., \& Gertler, M. (2006). Victual vicissitudes: Consumer deskilling and the (gendered) transformation of food systems. Agriculture and Human Values, 23(2), 143-162.

Lewis, D. (2015). Gender, feminism and food studies. African Security Review, 24(4), 414-429.

McPhail, D., Chapman, G., \& Beagan, B. (2011). “I don’t want to be sexist with my food”. The continued salience of gender in food choice. Appetite, 56(2), 537-538.

Metcalfe, A., Riley, M., Barr, S., Tudor, T., Robinson, G., \& Builbert, S. (2013). Food waste bins: Bridging infrastructures and practices. In D. Evans, H. Campbell, \& A. Murcott (Eds.), Waste matters: New perspectives on food and society (pp. 135-155). Hoboken: Wiley-Blackwell. 
Milne, R. (2013). Arbiters of food waste: Date labels, the consumer and knowing good, safe food. In D. Evans, H. Campbell, \& A. Murcott (Eds.), Waste matters: New perspectives on food and society (pp. 84-101). Hoboken: Wiley-Blackwell.

Quested, T. E., Marsh, E., Stunell, D., \& Parry, A. D. (2013). Spaghetti soup: The complex world of food waste behaviours. Resources, Conservation and Recycling, 79, 43-51.

Roshanafshar, S., \& Hawkins, E. (2015). Food insecurity in Canada. Statistics Canada Catalogue no. 82-624-X. Retrieved from http://www.statcan.gc.ca/pub/82-624x/2015001/article/14138-eng.htm

Waitt, G., \& Phillips, C. (2015). Food waste and domestic refrigeration: A visceral and material approach. Social \& Cultural Geography, 9365, 1-21.

Wang, C. (1999). Photovoice: A participatory action research strategy applied to women's health. Journal of Women's Health, 8(2), 185-192.

Watson, M., \& Meah, A. (2013). Food, waste, and safety: Negotiating conflicting social anxieties into the practices of domestic provisioning. In D. Evans, H. Campbell, \& A. Murcott (Eds.), Waste matters: New perspectives on food and society (pp. 102-120). Hoboken: Wiley-Blackwell. 